a level with the umbilicus, then becoming sharply recurved and ascending to the pylorus. The distension was not limited to the stomach but involved also the whole of the cluodenum, stopping short near the jejunum. The interior of the stomach showed no gross disease ; its contents were partly fluid and partly gaseous. The intestines below the duodenum were partially collapsed. The liver appeared to be fatty, the spleen was firm and slightly enlarged, and the kidneys were somewhat swollen, probably as the result of tubal changes. The portal and biliary systems were natural. There was no peritonitis. (For the clinical notes of this case we are indebted to the courtesy of Dr. Hector Mackenzie.)

In our previous paper we particularly drew attention to the fact that the dilatation was not neccssarily limited to the stomach but in four of the cases involved the duodenum as well, and in one of these four the first part of the jejunum was said to be also dilated. In both the cases we now record the duodentm was dilated, in one a part ancl in the other practically the whole of the duodenum being involved. In one of the cases lately recorded by Dr. Campbell Thomson a similar condition of affairs was noted. In the face of this evidence it seems impossible to maintain any longer, as some apparently still do, that the dilatation is due to pyloric spasm. The presence of bile in the stomach contents is additional evidence against spasm of the outlet of the stomach.

One point was very noticeable at the operation on our previous and first case: it was that the stomach was so tensely distended that it actually emitted a musical sound when an attempt was made to pick up its wall. Now it is impossible to believe that a paralytically distended viscus could be placed in a condition of tension so yreat as this without some mechanical obstructive factor. The question is, How is the obstruction produced? So far as we can gather from literature the advocates of mechanical obstruction of the duodenum incline to one of two views-either the duodenum is kinked by depression of the distended stomach or it is compressed by the root of the mesentery and superior mesenteric vessels which cross it. The advocates of the latter view postulate a primary collapse of the intestine and prolapse of the empty coils, such as to cause dragging on the root of the mesentery and superior mesenteric vessels.

We have found by actual experiment on the cadaver that the stomach can be enormously distended by water pressure, with the jejunum cut right across and lying patent in the abdomen. Moreover, the stomach remains thus distended. The same result can be attained after the superior mesen. teric vessels and the peritoneal folds in their neighbourhood have all been divided. If, however, by introduction of the finger well behind the distended stomach a little to the left of the mid-line of the spinal column the fundus and posterior wall of the stomach be gently raised the excess of fluid will at once flow freely away from the stomach through the cut jejunum. If the part of the duodenum which lies on the right side of the spine, behind the peritoneum, be first incised, the tense distension of the stomach cannot be produced. We therefore feel justified in assuming that the tense distension is due to actual pressure of the stomach on the part of the duodenum which crosses the third and ascends by the side of the second lumbar vertebra to end in the jejunum.

We would suggest, therefore, that in producing the train of symptoms met with in acute dilatation of the stomach two factors come into play. There is first a paralytic condition of the viscus which leads to distension, and then, at a certain stage the distended stomach actually produces obstruction by pressing on the duodenum on the front and to the left of the spinal column.

The persistence of the vomiting is often held to controvert the idea that the primary lesion is paralytic. It is well to bear in mind the present teaching of physiology on this question. Vomiting may be induced by the injection of tartar emetic into the blood, even after the stomach has been replaced by a bladder, provided that the cardiac orifice has also been removed so that the blaclder is actually tied into the cesophagus. If the cardiac orifice be left intact vomiting cannot be induced. Two factors are therefore essential for the production of vomiting: (1) a dilatation of the cardiac orifice and (2) compression of the stomach by the abdominal muscles and diaphragm or in some cases by the diaphragm only. The presence of the power to vomit is not therefore evidence that the stomach is not paralysed.

Acutely distended stomachs usually contain a quantity of gas as well as of bilious fluid. It is quite possible that a large quantity of this usually, but not always, odourless gas is derived from air which is consciously or unconsciously swallowed, and helps to increase the gastric distension. At the same time saliva is also swallowed, the patient's thirst leads him to drink freely, and possibly gastric hypersecretion also comes into play. When vomiting ceases in cases of acute dilatation of the stomach apparently the abdominal distension becomes extreme.

The early diagnosis of the affection is a point of no little importance. Treatment is apparently futile when the distension becomes extreme. It remains to be seen what can be effected by judicious management in the earlier stages of the affection. A consideration of the recorded cases shows that the recognition of the conclition is by no means easy. It has been mistaken for (1) intestinal obstruction, (2) perforative peritonitis, (3) perforation of bowel with encysted abscess, (4) pancreatic cyst, (5) uræmia, and (6) postanæesthetic vomiting. 1. Of obstruction it doubtless is form, but of obstruction high up, with obtrusive abdominal signs in the form of gastric dilatation. It must be noted, however, that diarrhcea is present and severe in some cases. 2,3 , and 4 . The intense abdominal pain which is usually present, the vomiting, the increasing abdominal distension, and the very marked collapse closeiy mimic general peritonitis. The position of the percussion dulness in the lower part of the abdomen and right iliac region may on a superficial examination appear to confirm this suspicion. The enormously distended stomach has even been mistaken for an encysted abscess. 5. The incessant vomiting, the partial suppression of urine, the occasional albuminuria, the condition of somnolent delirium which may mark the approaching termination, and the "collapse" temperature which is sometimes but not always present, may well give rise to suspicions of uræmia. 6. In those cases which occur after operations there is a great danger of attributing the vomiting to the anesthetic and the collapse to the operation. Careful examination of the abdomen in these cases is the only safeguard.

In all cases the readiest way to a diagnosis lies in a knowledge of the conditions under which acute dilatation of the stomach is likely to occur and in a careful physical examination of the abdomen with an attempt to elicit the succussionsplash.

We pointed out in our other paper that the gastric dilata tion may not at the onset of symptoms assume the extreme degree seen in the later stages of the disease, and that even a day or two may elapse before dilatation is recognised.

It must be borne in mind that the course of the temperature is variable and is largely influenced by the accom panying disease ; a "collapse" temperature is not necessarily present.

The general lines of treatment by strychnine injection, stomach lavage, rectal feeding, and intravenous or rectal saline infusion, have been insisted upon again lately. With regard to an attempt to remedy the obstruction by the postural method we can only say that, we have not been able to satisfy ourselves that it is successful in the cadaver, even with the abdomen freely opened, so that the stomach might fall forwards easily. It would appear rational, however, to adopt the right-sided or prone position after syphonage. It might be advisable also to try the effect of atropine injection, this method being believed by some to be of utility in the cardio-gastric crises of diphtheria. In these, however, obvious dilatation of the stomach is a very uncommon occurrence. Should operation be determined upon the ideal proceclure would certainly appear to be gastro-jejunostomy, as proposed by Mayo Robson in his remarks on the subject. ${ }^{6}$

\section{BRIEF NOTES OF A FEW EXCEPTIONAL CASES OF CATARACT EXTRACTION.}

\section{BY CHARLES BELL TAYLOR, M.D. EDIN.}

SURGEON TO THE NOTTINGHAM AND MIDLAND EYE INFIRMARY.

CASE 1. - This patient, from Middlesbro', was born with opacity of the lens in each eye, not the ordinary form of congenital cataract with an opaque centre and clear margin, but with an opacity affecting the lens throughout, slight at first and not sufficient to prevent his learning to read and to write, but gradually increasing: 
until at seven years of age the right eye was quite blind and the left so imperfect that in order to see ever so little he was obliged to hold objects literally in contact with his nose. When I first saw him he had been blind-that is, with only perception of light-for upwards of 35 years in the right eye and the left was not much better, the vitreous was fluid in both eyes, the iris was tremulous, and the lens shared in the general commotion whenever he moved his head. In these circumstances it was clear that any operative procedure would be attended with considerable risk; indeed, he had been treated as an in-patient and as an out-patient at a large ophthalmic hospital and had been strongly advised by one of our most eminent surgeons not to submit to any operation upon his eyes. Nevertheless, as matters were getting worse and he could neither enjoy life nor get his living, I decided to operate upon the right eye; this I did in the ustual way, with a small flap upwards, and, contrary to my usual custom, a slight iridectomy. The vitreous drained away the moment the section was completed, the eyeball collapsed, and the lens sank to the bottom of the chamber ; I therefore coaxed it out with my wire spoon, an invaluable instrument, since its extreme tenuity enables the operator to assist the exit of the lens without adding to its bulk (see Fig. 1). All went well

FIG. 1.

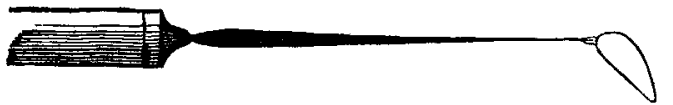

and the patient recovered without a bad symptom. I therefore repeated the same process on the left eye which also recovered, and this patient now has excellent sight. Here is what he writes on the subject: "I am so thankful to say my eyes are splendid now, I have not had the least pain whatever and can see any distance. I have been taken to church, chapel, and lectures many a time, but never saw the speaker till last Sunday. Things are so different to what I thought they were, it is a new world altogether, oh, dear ! after being in darkness for over 37 years and then to recover my sight, I am bewildered and could weep for joy."

CASE 2.-The patient, who was 42 years of age, was struck in the right eye by a piece of steel 15 years ago and the sight of this eye was in consequence completely lost. A year ago the same accident happened to the left eye, and after residence for a month in a large ophthalmic institution he was discharged on the ground, according to his own account, that "it was not possible to do anything for him." The case was certainly complicated and unpromising, but I saw no reason why an attempt should not be made to restore his sight. I therefore operated four times, extracting the lens in each eye and forming an artificial pupil in both. Suffice it to say that he has recovered sight, so good that he is now employed as manager of a large store, a position in which accurate vision both for distance and for near objects is essential.

CASE 3.-The patient, a woman, aged 45 years, lost her right eye 17 years ago from an accidental blow, and recently while nursing a friend's child she contracted purulent ophthalmia, followed by panophthalmitis, shrinkage, and complete loss of the left eye. She had been treated with the utmost care and skill in an ophthalmic institution, and when all hope of restoring sight to the left eye was abandoned she was placed under chloroform with a view to operation upon the right eye, which had been blind so long (17 years). 'This intention was, however, abandoned by the surgeon at the last moment and on recovery from the anæs thetic sleep she was informed that nothing had been done or would be attempted as the case was hopeless. When I first saw her I found that she was suffering from "cataracta complicata accreta," that the vitreous was fluid, that the iris was tremulous, and that the prospects of restoration of sight by operation were very small indeed. I dared not give an anæsthetic for fear of sickness and excitement, and it was only by a combination of cocaine, holocaine, and what might fairly be called hypnotism that I succeeded in doing a small iridectomy upwards and removing the lens capsule and all entire with iris forceps, leaving a perfectly black pupil, through which she now has excellent vision both for reading and writing and is able to resume her former occupation - that of a teacher of music.

CASE 4. - The patient, a man, aged 74 years, had long suffered from cataract in both eyes; the left had been blind for years and recently the right had become similarly affected. When I first saw him the cataract had been removed from the right eye by a well-known and experienced ophthalmic surgeon, but with unfortunately disastrous results. 'The patient's son informed me that before the operation he could see to go about with the operated eye, although the left was quite blind, and I naturally asked, "Why did you have an operation on the best eye when the left, blind so long and with everything to gain and nothing to lose, was inviting interference?" To which he replied that the operating surgeon had said "that the reason why he selected the right eye for operation was because he could use his right hand so much better than his left." I mention this merely to call attention to my bent knife, by which the left eye may be operated upon with the right hand with even greater facility than may the right eye. I operated upon this patient's left eye with the knife in question (see Fig. 2),

FIG. 2.

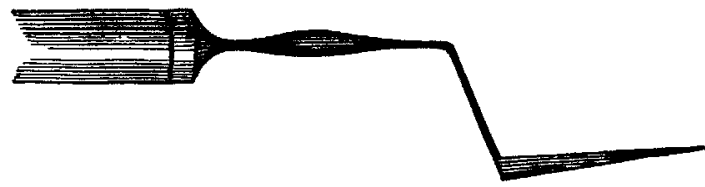

upwards without iridectomy and am thankful to say that he has now a perfect eye and excellent sight both for reading and for distance.

CASE 5.-The patient, who was blind from cataract in both eyes, was first operated on in Australia, the right eye being selected for extraction, an operation which was performed in the usual way upwards with iridectomy. Unfortunately, everything went wrong. The pupil closed, sight was lost (the retina was said to be detached), and the eye remained in a very irritable condition. In these circumstances it was deemed desirable that he should seek advice in the old country, and he accordingly came over and consulted some of our most eminent metropolitan ophthalmic surgeons, with the result that he was advised to submit to extirpation of the right eye before any operation was attempted on the left, and that he should be then safeguarded by a preliminary iridectomy with an interval of weeks or months before the cataract was extracted from the left eye. He did not see his way to fall in with these suggestions, and as the last surgeon whom he had consulted had told him that circumstances were not favourable for operation and that he had better return home he determined to do so, blind as when he came. At this juncture someone sent him to Nottingham. When I first saw him he was accompanied by a gentleman on whom I bad operated for cataract some years ago, and as this gentleman was very anxious to get away the same day I operated upon the patient's left eye at once, extracting in the usual way upwards under cocaine and holocaine and without iridectomy. All went well; he had no pain at the time and none after. There was no prolapse of the iris, the pupil was clear, round, central, and moveable, and the eye (a light grey) beautiful to look upon. It is almost needless to add that he recovered most excellent sight both for reading and for distance. The question now arose, what should be done with the right eye ? and some of his friends were very anxious that it should be excised before he incurred the risks of a voyage. No doubt this would have been a prudent course, but I never take an eye out if I can help it, and as the patient had good perception of light I performed a large iridectomy downwards, extracted a mass of capsule and punctured the hyaloid fossa, with the result that he has now very useful sight with this eye, being able to go about with his best eye closed and to read large print (double pica) with a glass.

CASE 6. - This patient came under my care in his eightysixth year, suffering from asthma, chronic bronchitis, and constant cough. He was blind from cataract in both eyes and had been advised by an ophthalmic surgeon not to submit to extraction. I operated upon the left eye without misadventure and without iridectomy ; there was no prolapse and as the pupil was certral and moveable I divided a small piece of capsule and sent him home within 14 days. Later the opening in the capsule closed and I therefore extracted it en masse with iris forceps. This operation was followed by an attack of acute glaucoma, which was instantly arrested by sclerotomy and puncture of the hyaloid fossa, and he has now excellent sight both for reading and for distance. The case is worthy of record as the patient, who 
keeps a public-house, is a life-long abstainer from all alcoholic liquids.

-CASE 7.-This patient also was in his eighty-sixth year when he came under my care. He was then suffering from cataract in both eyes, fully formed on the right eye and commencing on the left. I extracted on the right eye without iridectomy, restoring excellent sight. A decade later he expressed a wish to have the left eye operated on, and I repeated the same process without iridectomy on that eye. As he was in his ninety-sixth year I was anxious that he should be exposed to as little risk as possible and therefore treated him in $\mathrm{my}$ private hospital and surrounded him with every care

FIG. 3.

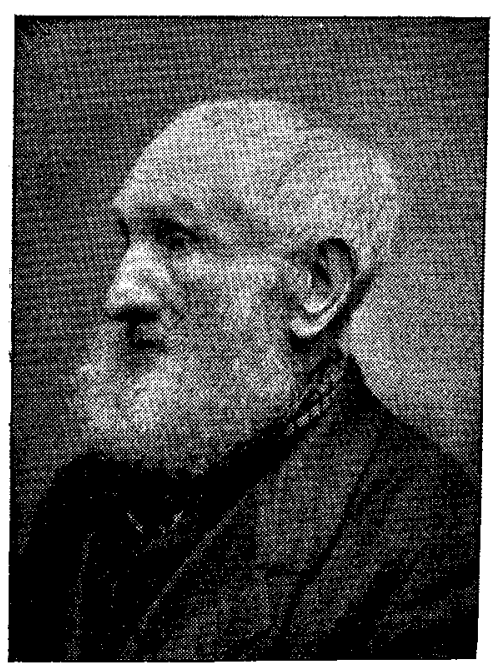

and attention. The day after the operation, however, he got up, dressed, and returned home, where there were no facilities for treatment whatever. Nevertheless, he made an excellent recovery without any prolapse of iris and has now in his hundred-and-first year most excellent sight both for reading and for distance. 'I'his case is remarkable and I therefore with his permission jresent your readers with a portrait of the Nottingham centenarian (see Fig. 3).

Nottingham.

\section{THE TREATIENT OF OZÆNA BY CUPRIC ELECTROLYSIS.}

By EUGENE S. YONGE. M.D. EDIN.,

HONORARY ASSISTANT PHYSICIAN, MANCHESTER HOSPITAL FOR CONSUMP'ION AYD DISEASES OF THE THROAT.

IT is probable that of all the nasal diseases which, by a somewhat haphazard nomenclature, have been loosely labeled "ozæna," fœetid atrophic rhinitis is the one for which the term has most frequently been used as a synonym. When employed in this specific sense it is understood to indicate a disease characterised by a chronic course, by atrophy of the nasal mucosa and sometimes of the osseous structures of the turbinateds and by the formation of fœtid crusts, and all this without definite discoverable cause.

Until within recent years the treatment of this malady was largely confined to dealing with the troublesome symptoms associated with the disease. It was found that by continned local measures the formation of crusts and the intense fotor could to a large extent be kept in abeyance; and inasmuch as these two disabilities when unchecked were almost as potent to banish the victim from society as was the power given by Kleisthenes to the Athenians, it must be admitted that this was something gained. For a long period, however, no noteworthy advance was made, and although remedies which were said to have healing properties were from time to time suggested it was not until the year 1892 that Jouslain ${ }^{1}$ proposed the method of cupric interstitial electrolysis which up to the present date appears to have progressed farthest in the direction of cure. Cheval described the procedure in 1895 and asserted that he had obtained 90 per cent. of cures, the majority of these after a single séance, but a committee appointed to investigate the

Moure: Bulletin de la Société Française d’Otologie \&c., tome xiii., matter by the Society of Belgian Laryngologists and Otologists, to whom he had communicated his paper, were far from being able to share his optimism. Bayer, ${ }^{2}$ Brindel, Gouguenheim and Lombard, ${ }^{3}$ and $\mathrm{McBride}^{+}$have all given their experiences of cupric electrolysis, and to the article by the last-named author I am much indebted.

I have had the opportunity of testing the efficacy of this treatment in 15 cases and the details of the method as employed are briefly as follows. The nasal cavities were first thoroughly cleaused by a warm alkaline and antiseptic douche. Cocaine was then applied to the nasal cavity to be treated, and after a few minutes the parts were dried and the electrolysis needles inserted. The copper needle, attached to the positive pole, was passed into the inferior or middle turbinal, usually the former, and the steel needle into the septum. 'The strength of the current varied, but it was found that from three to 10 milliampères were the most suitable intensities, although currents as strong as 20 milliampères were on a few occasions used. As a general rule, the current was allowed to pass for 10 minutes, and it appeared that no advantage accrued from prolonging the application beyond this period of time. After each séance the patient was usually instructed to refrain from syringing the nose until the next examination. The number of applications given depended upon the improvement noted; five séances were the maximum.

Although at least one death has been attributed to this treatment I did not myself observe any after-effects which were calculated to give rise to alarm. A patient occasionally complained of slight giddiness and some general disturbance after the application, a few stated that they suffered from neuralgic pains in the teeth and face, and one patient reported that there was some swelling of the face. Two children (aged 11 years and 14 years respectively) each developed a small perforation in the septum as one of the results of the treatment, but in neither case did the event give rise to any permanent inconvenience. With currents ranging from 5 to 10 milliampères there was considerable discomfort and the cocaine appeared to act only in reducing the amount of pain caused by the insertion of the needle; there was, however, a tendency for the unpleasant sensations caused by the passage of the current to become lessened in the course of a few minutes. In analysing my own observations I have divided the cases into (1) those in which the patients were cured; (2) those in which the patients were much improved; (3) those in which the patients were temporarily improved but relapsed; and (4) those in which the patients were not improved.

1. Cases in which the patients were cured. - These were two in number.

CASE 1.-The patient was a female, aged 38 years. There was a history of marked crusting and offensiveness for at least 15 years. Examination revealed considerable atrophy of the turbinals and marked crust formation. The patient was given two applications of electrolysis (one in each nostril) at the Manchester Throat Hospital in October, 1899. Since that time she has presented herself at intervals for re-examination and was last seen in October, 1901, but no crust or odour could be detected. She has therefore been free for two years. The patient thinks that her sense of smell has slightly returned.

CASE 2.-The patient was a female, aged 20 years. There was a history of considerable nasal discharge and crusting for several years. Fotor had been marked for at least 12 months. The patient was given two applications in December, 1900 . She had not syringed since that date and had not been troubled with foetor or crusting. Now (October, 1901) the nasal cavities are quite free from crusts or odour, although the atrophy of the turbinals persists. She has therefore been free from symptoms for 10 months.

2. Cases in which the patients nere much improved. -These cases amounted to five, all of whom with one exception (Case 3) were seen in October, 1901, and the reports were made at that date.

CASE 3.-The patient, a female, aged 26 years, came under treatment 18 months ago. When she was last seen she reported that she had had to syringe about four times in three months (as compared with twice daily before treatment). She had been much bothered with crusts in the naso-pharynx; when last seen, however, there was practically

2 Revue Hebdomadaire de Laryngologie, Mai, 1896. 8 Annales des Maladies de l'Oreille, November, 1898. 4 Gdinburgh Medical Journal, March, 1899. 